\title{
Enhancement of latent fingerprints on fabric using the cyanoacrylate fuming method followed by infrared spectral mapping
}

Article

Accepted Version

Sonnex, E., Almond, M. J. and Bond, J. W. (2016)

Enhancement of latent fingerprints on fabric using the cyanoacrylate fuming method followed by infrared spectral mapping. Journal of Forensic Sciences, 61 (4). pp. 1100-1106. ISSN 0022-1198 doi: https://doi.org/10.1111/1556-4029.13065 Available at https://centaur.reading.ac.uk/66613/

It is advisable to refer to the publisher's version if you intend to cite from the work. See Guidance on citing.

To link to this article DOI: http://dx.doi.org/10.1111/1556-4029.13065

Publisher: Wiley-Blackwell

All outputs in CentAUR are protected by Intellectual Property Rights law, including copyright law. Copyright and IPR is retained by the creators or other copyright holders. Terms and conditions for use of this material are defined in the End User Agreement. 


\section{CentAUR}

Central Archive at the University of Reading

Reading's research outputs online 


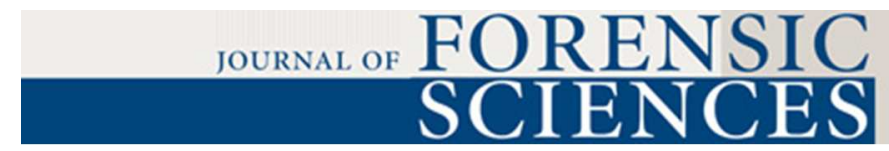

\section{Enhancement of Latent Fingerprints on a Fabric using the Cyanoacrylate fuming method followed by Infrared spectral mapping}

\begin{tabular}{|r|l|}
\hline Journal: & Journal of Forensic Sciences \\
\hline Manuscript ID: & JOFS-15-125 \\
\hline Danuscript Type: & Technical Note \\
\hline Complete List of Authors: & $\begin{array}{l}\text { Sonnex, Emily; University of Reading, Department of Chemistry } \\
\text { Almond, Matthew; University of Reading, Chemistry } \\
\text { Bond, John; University of Leicester, Chemistry }\end{array}$ \\
\hline Keywords: & $\begin{array}{l}\text { forensic science, fingerprint, infrared, microscopy, principal component } \\
\text { analysis, fabrics, cyanoacrylate fuming }\end{array}$ \\
\hline \multicolumn{2}{|c}{} \\
\hline
\end{tabular}

\section{SCHOLARONE ${ }^{\text {m }}$ \\ Manuscripts}




\title{
Enhancement of Latent Fingerprints on a Fabric using the Cyanoacrylate fuming
} method followed by Infrared spectral mapping

\begin{abstract}
A method has been developed for the visualisation of latent fingerprints on various fabrics. The method is based upon cyanoacrylate (superglue) fuming, followed by imaging using an infrared microscope. The method works best on smooth, shiny fabrics and has been shown to work on polyester, silk, nylon and acetate fabrics of different colours and patterns and has shown an improvement over existing proposed methods. It would be quite possible for this method to be adopted by forensic practitioners. It has been shown that ageing has little effect on the results of the method for the time scale that has been studied here. Some very striking results are obtained where visual inspection shows little contrast to the superglued print while a very clear contrast is seen when IR microscopy is utilised. Methods using both infrared mapping of a specific frequency range and principal component analysis (PCA) have been studied and it is found that the best results are obtained by PCA.
\end{abstract}

\section{Introduction}

There are currently many different methods for the enhancement of fingerprints on different surfaces. For example cyanoacrylate fuming (CAF) is often used for plastic surfaces, Ninhydrin is used for light coloured paper and various metal deposition techniques are used for metal surfaces $(1,2,3)$. There is currently no recognised method for the enhancement of fingerprints on fabric and Forensic Investigation Units in the UK currently do not attempt to recover fingerprints from such garments (1). It is therefore clear that a method that allows prints on fabrics to be successfully enhanced would be a large step forward in fingerprint enhancement and identification.

Little previous work has attempted to enhance prints on fabric because of its difficult nature, and no one has yet developed a completely successful method. The most successful work done so far has utilised vacuum metal deposition (VMD) to enhance prints on a range 
of fabrics $(4,5,6)$. This technique deposits metal onto the fabric under vacuum conditions while the fabric under the fingerprint ridges is shielded from the metal by the print residue, leaving a negative image of the print (7). Prints were obtained on a range of fabrics; polyester, nylon and cotton. However, while this method has been the most successful to date, the majority of the prints were 'empty'. That is, they contain no ridge information, just an impression of a grab mark. While this does not allow for identification of a suspect, it can be confirmed that an item has been grabbed in a certain way and also allows for further testing in that area of the item, e.g. DNA swabbing. This method is neither simple nor cheap to carry out and because of this, coupled with its limited results, it is not particularly viable at this stage.

The use of cyanoacrylate fuming followed by the use of a dye on fabrics has also been investigated by Fraser et al (6) and the results compared to those of the VMD method. It was found that very few prints gave any ridge detail or indication that the fabric had been touched. These workers found that Nylon was the only fabric to show any impression mark, perhaps due to its very smooth, almost waterproof surface that would not absorb the dye so readily.

It is possible that cyanoacrylate is able to polymerise onto the ridges of a latent fingerprint on a range of fabrics, but obtaining a visible contrast is difficult. Dying techniques which are currently the only method of further enhancing a cyanoacrylate fumed print are often not successful because of the porous nature of the fabrics. The research described in this paper is based on the proposal that if the cyanoacrylate adheres to the fingerprint ridges sufficiently, while it is not clearly visible by eye, there is a contrast in chemical composition between the cyanoacrylate and fabric that may be observed by an infrared spectrometer. An infrared microscope may then allow a spectral map to be recorded of the fingerprint and an image of the ridges produced. This procedure, of imaging a print with an infrared 
microscope, has already been carried out on other surfaces and has shown to be successful (8). Therefore, if it is possible for cyanoacrylate to polymerise on the fingerprint ridges on a fabric, this method should provide a good image of a fingerprint.

It is likely that the success of this method will be determined mostly by the nature of the fabric used. A fingerprint may either sit on top of a fabric or be absorbed into it, affecting how well the print can be enhanced. The thread count of the fabric will affect the quality of the print; a tighter weave will allow for a better print to be produced as there will be fewer gaps in the fabric. And finally, whether a fabric is natural or synthetic may affect how well the print is absorbed into the fabric. Some synthetic fibres are manufactured to have good wicking properties, that is, they allow for easy evaporation of sweat residues, while fabrics such as cotton may hold onto sweat and fingerprint residues much more (9).

The UK manual of fingerprint development techniques states that there is 'no proven process' for the enhancement of fingerprints on fabric and outlines some conditions that any such method must meet. Any fabric chosen must have a thread count no less than three threads per millimetre and must be clean (1). The thread count is important as large gaps in the weave of the print will not allow for continuous ridges to be observed, and may distort the fingerprint image obtained. It will be ensured that all fabrics used in this research meet these requirements by examining the fabric under a microscope.

This research aims to investigate whether the use of spectral mapping by infrared microscopy after the application of cyanoacrylate fuming is a possible and viable forensic technique for the enhancement of fingerprints on fabric and whether it will provide an improvement over existing or other proposed techniques. Different fabrics of different colours and patterns will be tested to see if this affects the quality of results, as well as 
determining if different donors and the age of the print will have an effect on the success of enhancing a print.

\section{Materials and methods}

\section{Fabrics}

Six different fabrics were used in this research: polyester, nylon, cotton, poly-cotton (a mix of 35\% cotton and 65\% polyester), silk and acetate (all obtained from John Lewis department store, Reading, UK). All fabrics had a thread count of 3 threads per millimetre or greater and were all washed with biological liquid detergent before use to remove any contaminants.

The repeat experiments were carried out with a total of 15 donors (male and female, ages 22-65) placed natural grab marks onto swatches of fabric $(20 \mathrm{~cm} \times 20 \mathrm{~cm}$ in size and washed prior to use with biological liquid detergent to remove any contaminants) by placing the swatch over the arm and grabbing with medium strength for 5 seconds to simulate an attacker grabbing a victim by the arm. The swatches were then stored in plastic wallets, in the dark at room temperature until the prints were enhanced. The prints were stored for the following durations:

$1,2,3,4,7,10,14,21$ and 28 days

\section{Cyanoacrylate fuming}


A commercial fuming chamber was not available for this research, so cyanoacrylate fuming was carried out with apparatus that has been shown to give good, reproducible results, as shown by Nixon (10). The apparatus, as shown in Figure 1, was set up to mimic the operation of a commercially available fuming chamber.

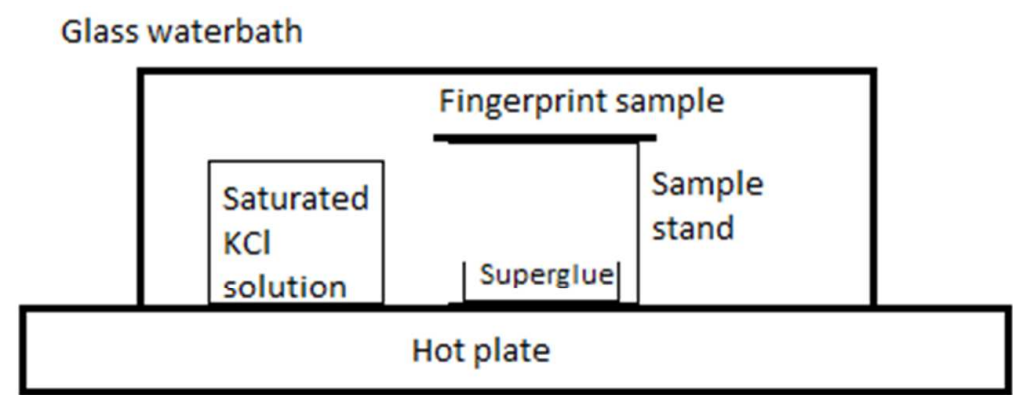

Figure 1 Cyanoacrylate fuming equipment schematic

A constant temperature of $90^{\circ} \mathrm{C}$ was maintained by the hot plate. At this temperature, a relative humidity of $78.50 \pm 1.0 \%$ was obtained by the saturated potassium chloride solution which is close to the $80 \%$ humidity provided in commercial chambers $(11,12)$. The fingerprint sample was suspended on a stand, print side down, above the cyanoacrylate to maximise adherence of the cyanoacrylate onto the print. Once the set temperature had been reached, four drops of cyanoacrylate (Crime Scene Investigation, Woburn Sands, UK) were added into the aluminium foil dish, the glass water bath replaced and the prints left between 12-18 minutes. Several sample stands could be used at once to allow multiple prints to be fumed at the same time.

This apparatus has previously been developed and proven by C Nixon (10) and it was found that the above apparatus gave repeatable results on a range of substrates and gave the best results out of a range of different apparatus set-ups. It was also found that a consistent weight was obtained when four drops of cyanoacrylate were repeatedly dispensed and 
weighed. Therefore, it is not necessary to weigh the exact amount of cyanoacrylate used each time.

\section{Instrumentation}

The Perkin Elmer Spectrum 100 FT-IR spectrometer with Perkin Elmer Spotlight 400 FT-IR (Beaconsfield, UK) imaging system attachment was used to produce all spectral maps in this research. The following parameters have been used: Wavenumber: 4000-680 cm-1;

Resolution: $8 \mathrm{~cm}^{-1}$; Scans per pixel: 16 ; Pixel size: $25 \mu \mathrm{m}$; Interferometer speed: $1.0 \mathrm{cms}^{-1}$.

\section{Results}

It was first necessary to consider the chemical composition of each fabric and to determine whether a chemical contrast would be obtained between the fabric and cyanoacrylate polymer. As each of the fabrics used in this research has a different chemical composition, and so a different IR spectrum, it may be difficult to find a chemical contrast between cyanoacrylate polymer and the fabric that applies in all cases. To assess this, a spectral map of a fingerprint on a brass substrate (so that the background does not interfere with the spectrum) that has been subjected to cyanoacrylate fuming has been recorded and is shown in Figure 2. The map shows a section that is approximately three ridges wide.

It was found that the carbonyl peak at $1700 \mathrm{~cm}^{-1}$ is the best spectroscopic feature to map to produce a good image of the print. Principal component analysis, also shown in Figure 2 (right), shows an even clearer image of the fingerprint ridges. This approach also cancels out the weave pattern of the fabric. This provides the best method of imaging 
fingerprint ridges that have been subjected to cyanoacrylate vapours. When other peaks were mapped, the fingerprint produced was not satisfactory. Principal component analysis identifies different components within the spectra that are not easily picked out by eye; the software then maps these components to show their distribution over the area studied. This can allow slightly different images to be produced compared to the mapping of a single peak.
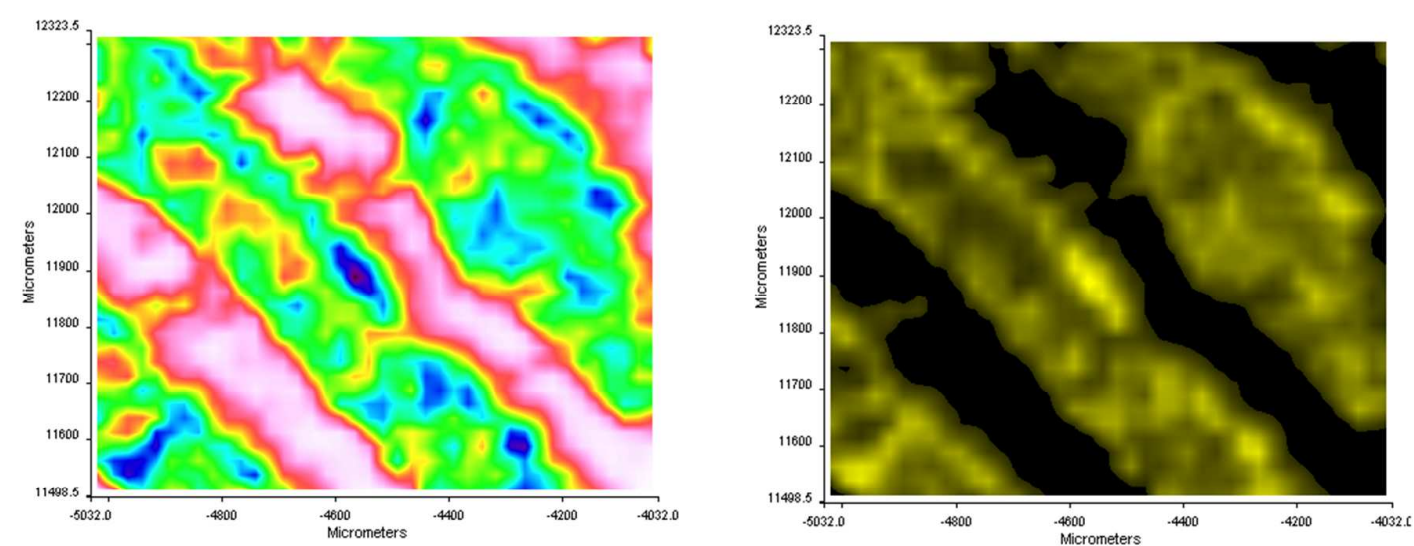

Figure 2 IR maps showing three ridges of a fingerprint on a brass substrate Left: map of the carbonyl peak from cyanoacrylate, Right: mapped by principal component analysis

While the mapping of the carbonyl peak gave a good image on a brass substrate, fabric may not be as successful. Carbonyl is a common functional group and is present in many fabrics. Polyester, for example, shows a peak at $1700 \mathrm{~cm}^{-1}$ which arises from the $v(\mathrm{C}=\mathrm{O})$ vibration, as does polycotton. It is for this reason that polyester and polycotton may be the least suitable fabric for this experiment as a chemical contrast may not be easily obtainable. However, the physical properties of the fabric are also important. Polyester and nylon fabrics are both smooth, shiny materials which may allow for better adhesion of fingerprint residues, as well as cyanoacrylate polymer and so may produce a better quality fingerprint. 
Natural fingerprints, those that have not been groomed in any way, were deposited onto samples of each of the six fabrics; nylon, polyester, cotton, polycotton, acetate and silk. The fabrics were all dark in colour as this would give the most chance of being able to see a visual contrast between the cyanoacrylate and the fabric to assess whether the technique is suitable. The fingerprints were cyanoacrylate fumed with the prints being left in the fuming chamber for between $12-18$ minutes (longer than is often required for prints on non-porous surfaces). A photo of the print on dark polyester is shown below in Figure 3. The print has been enhanced well, with significant ridge detail visible and the cyanoacrylate deposits can quite clearly be seen here as the white of the cyanoacrylate polymer contrasts with the dark fabric. This photo shows that the print has been fully developed and that it is quite possible to use cyanoacrylate fuming for prints on polyester.

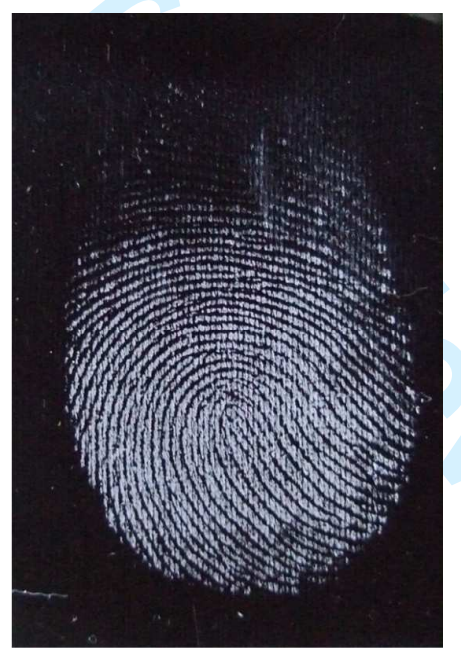

Figure 3 Photo to show a fingerprint on dark polyester after cyanoacrylate fuming

A latent print was also successfully enhanced on dark nylon, dark acetate and dark silk with this method and a good quality print was obtained with clear ridge detail on each. 
Cotton and polycotton however, were not successful and produced no visible print. This is likely to be due to the more porous nature of cotton based fabrics compared to synthetic fabrics.

These experiments show that it is quite possible to get cyanoacrylate to polymerise on a fingerprint on certain fabrics. The fabrics used so far have all been dark in colour and so a visual contrast has been obtained. When no visual contrast is clear, the current method in the UK is to subsequently dye the print with basic Yellow 40 dye (1). This however would not work well for light fabric samples as the dye would soak into the entire fabric substrate. Therefore, it would be difficult to achieve a visual contrast if a lighter coloured fabric has been used as without dyeing, no contrast is visible between the white polymer and the fabric. Thus, while it is possible to see the cyanoacrylate polymer on the print visually on some dark fabrics, for the enhancement of fingerprints on light coloured fabrics, a further step is needed to be able to obtain a good fingerprint image. Instead of relying on a visual contrast between the cyanoacrylate polymer and the fabric background, we have instead investigated the chemical contrast between the two. To do this, infrared microscopy has been used, after the print has been subjected to cyanoacrylate fuming, to see if it is possible to obtain a spectral map of the fingerprint.

The print produced previously (Figure 4) on black polyester was mapped using the infrared microscope. The print on black polyester was tested initially, as even though a visual contrast could be seen between the white polymer and the background, it was essential to know if the cyanoacrylate polymer could be mapped by infrared spectroscopy. Figure 4 shows the spectral map produced of the print as processed with principal component analysis 


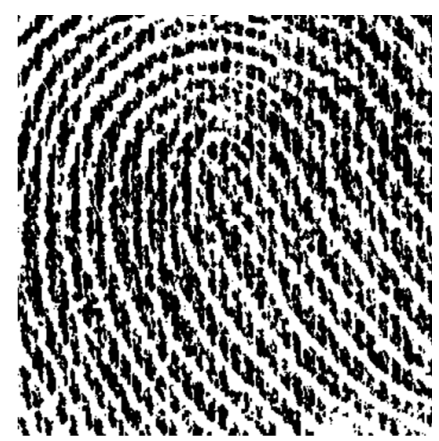

Figure 4 Image of a print that has been mapped by an infrared microscope and processed with principal component analysis.

The prints on dark nylon, dark acetate and dark silk were also successfully imaged in this way.

Once it was determined that prints on dark fabric could successfully be enhanced by first subjecting them to cyanoacrylate fuming and then mapping them with an infrared microscope, light fabrics were investigated. This method will hereafter be referred to as ' $\mathrm{CAF}$ \& FT-IR'.

It has been deemed that cotton and polycotton are not suitable fabrics for this as they would not allow cyanoacrylate polymer to adhere to the fabric. Therefore, only light polyester, light nylon, light acetate and light silk have been trialled. Natural prints were applied to the light coloured fabrics and subjected to cyanoacrylate fuming. The cyanoacrylate could not be seen easily due to the lack of visual contrast between the white cyanoacrylate polymer and the white fabric. However, when held at a certain oblique angle in the light, it was possible to see that a fingerprint was present, but no detail was visible. The prints were successfully mapped with an infrared microscope in the same way as for the dark fabrics and an image of a print on light acetate is shown in Figure 5. 
Patterned fabrics were also investigated to determine whether the pattern of the fabric

Figure 5 Left: Visual image of cyanoacrylate on light acetate. Right: Spectral image of cyanoacrylate on light acetate.

could be removed by principal component analysis. Often, when enhancing prints on patterned surfaces, porous or non-porous, it can be difficult to get a good visual contrast between the colours in the pattern and the colour of the chosen enhancement technique. Fluorescent dyes or powders are often used in this case for non-porous surfaces. However, the CAF \& FT-IR method worked well for patterned fabrics as the chemical contrast between the cyanoacrylate and fabric still remained. Only patterned polyester and patterned silk were available; both allowed a fingerprint to be successfully imaged. An image of patterned polyester can be seen in Figure 6.
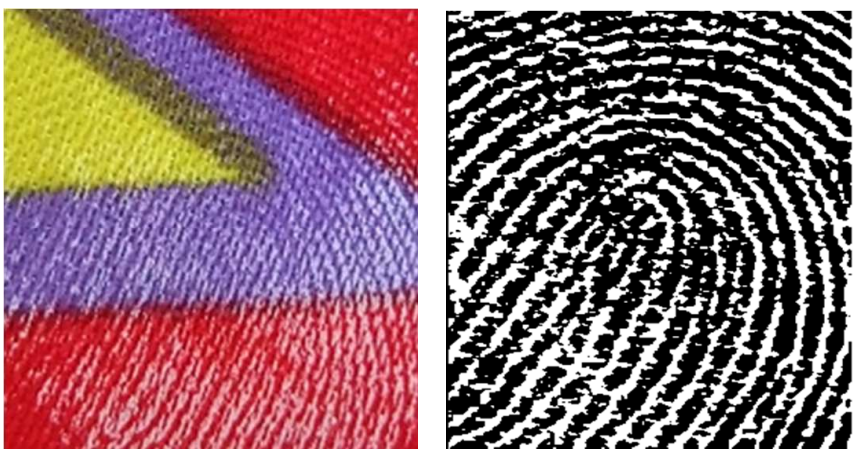

Figure 6 Left: Visual image of cyanoacrylate on patterned polyester. Right: Spectral image of cyanoacrylate on patterned polyester. 
Table 1 shows a summary of the fabrics on which a cyanoacrylate fumed fingerprint was successfully mapped by infrared spectroscopy.

Table 1 Summary to show on which fabrics and colours a fingerprint was enhanced by CAF \& FT-IR. (*Fabric was not available and so enhancement has not been carried out)

\begin{tabular}{|c|c|c|c|}
\hline & Dark & Light & Patterned \\
\hline Polyester & $\checkmark$ & $\checkmark$ & $\checkmark$ \\
\hline Nylon & $\checkmark$ & $\checkmark$ & $*$ \\
\hline Acetate & $\checkmark$ & $\checkmark$ & $*$ \\
\hline Silk & $\checkmark$ & $\checkmark$ & $\checkmark$ \\
\hline Cotton & x & x & x \\
\hline Polycotton & X & x & x \\
\hline
\end{tabular}

It has been determined that the method of CAF \& FT-IR outlined in this research provides a technique that can successfully enhance prints of a good quality on a range of fabrics of different colours and patterns. To test the repeatability of the method, multiple prints from different donors have been tested.

It was decided that to develop the method further and to test its repeatability; only one fabric would be used from this point forward. Polyester is perhaps the most common of these fabrics to be found in clothing; it is far more common than silk, acetate or nylon and so was deemed to be a sensible choice. It also allowed for good polymerisation of cyanoacrylate onto the fingerprint ridges on the fabric and good spectral maps were also produced when this fabric was used.

The repeatability of the method was tested by placing grab marks onto swatches of the fabric and then treating the samples with cyanoacrylate fuming in the same way as before. 
Other work in the area of fingerprint enhancement on fabrics demonstrates a similar approach to test their method (4). Dark polyester was chosen as it is possible to determine whether a print has been enhanced before the additional step of imaging with FT-IR. It has already been determined that an accurate spectral map can successfully be obtained from a print that has successfully been enhanced with cyanoacrylate fuming.

In total 135 prints were tested. The prints were not groomed in anyway and were deposited after normal daily activities, ensuring that only what was already on the donors hand was deposited. Prints from the same donor were taken at least an hour apart to ensure that there was a good supply of eccrine and sebaceous deposits on the hand.

The prints were all subjected to cyanoacrylate fuming in the same way as before and were typically left in the fuming chamber for between $12-18$ minutes. Each print was photographed and given a score from 0-4 based on the Bandey scale as shown in Table 2 (13). The results are as shown in Table 3.

Table 2 The Bandey five-point scale for grading of ridge detail on fingerprints

\begin{tabular}{|c|l|}
\hline Grade & Comments \\
\hline 0 & No Development \\
\hline 1 & No continuous ridges; all discontinuous or dotty \\
\hline 2 & $\begin{array}{l}\text { One-third of mark continuous ridges; rest no development or } \\
\text { dotty }\end{array}$ \\
\hline 3 & Two-thirds of mark continuous; rest no development or dotty \\
\hline 4 & Full development; whole mark continuous ridges \\
\hline
\end{tabular}

Table 3 Results of the grab marks from 15 donors over 9 time points. The right hand of each column shows the Bandey scores for each print and the left hand side shows a yes (y) or no (n) indication of a grab mark being present. 'Identifiable' prints (that is, those that scored a 3 or 4) are highlighted in light grey. Prints with no indication of a print or grab mark are highlighted in dark grey.

\begin{tabular}{|c|c|c|c|c|c|c|c|c|c|}
\hline Donor & Day 1 & Day 2 & Day 3 & Day 4 & Day 7 & $\begin{array}{c}\text { Day } \\
10\end{array}$ & $\begin{array}{c}\text { Day } \\
14\end{array}$ & $\begin{array}{c}\text { Day } \\
21\end{array}$ & $\begin{array}{c}\text { Day } \\
28\end{array}$ \\
\hline 1 & Y 4 & Y 4 & Y 4 & $\begin{array}{ll}\mathrm{Y} & 1\end{array}$ & Y 3 & $\begin{array}{ll}\text { Y } & 1\end{array}$ & $\mathrm{Y}$ & $\begin{array}{ll}\text { Y } & 1\end{array}$ & Y 3 \\
\hline
\end{tabular}




\begin{tabular}{|l|ll|ll|ll|ll|ll|ll|ll|ll|ll|}
2 & $\mathrm{~N}$ & 0 & $\mathrm{~N}$ & 1 & $\mathrm{~N}$ & 0 & $\mathrm{Y}$ & 1 & $\mathrm{~N}$ & 0 & $\mathrm{~N}$ & 0 & $\mathrm{~N}$ & 0 & $\mathrm{Y}$ & 1 & $\mathrm{~N}$ & 1 \\
3 & $\mathrm{~N}$ & 0 & $\mathrm{~N}$ & 1 & $\mathrm{Y}$ & 1 & $\mathrm{~N}$ & 0 & $\mathrm{~N}$ & 1 & $\mathrm{~N}$ & 1 & $\mathrm{~N}$ & 0 & $\mathrm{~N}$ & 1 & $\mathrm{~N}$ & 0 \\
4 & $\mathrm{Y}$ & 2 & $\mathrm{Y}$ & 1 & $\mathrm{Y}$ & 1 & $\mathrm{~N}$ & 1 & $\mathrm{Y}$ & 1 & $\mathrm{Y}$ & 1 & $\mathrm{Y}$ & 1 & $\mathrm{~N}$ & 0 & $\mathrm{~N}$ & 0 \\
5 & $\mathrm{Y}$ & 1 & $\mathrm{Y}$ & 1 & $\mathrm{Y}$ & 3 & $\mathrm{Y}$ & 2 & $\mathrm{~N}$ & 1 & $\mathrm{~N}$ & 0 & $\mathrm{Y}$ & 3 & $\mathrm{Y}$ & 0 & $\mathrm{Y}$ & 2 \\
6 & $\mathrm{Y}$ & 1 & $\mathrm{Y}$ & 4 & $\mathrm{Y}$ & 1 & $\mathrm{~N}$ & 0 & $\mathrm{Y}$ & 3 & $\mathrm{Y}$ & 1 & $\mathrm{Y}$ & 2 & $\mathrm{Y}$ & 1 & $\mathrm{Y}$ & 1 \\
7 & $\mathrm{Y}$ & 3 & $\mathrm{Y}$ & 4 & $\mathrm{Y}$ & 3 & $\mathrm{Y}$ & 3 & $\mathrm{Y}$ & 3 & $\mathrm{Y}$ & 2 & $\mathrm{Y}$ & 1 & $\mathrm{Y}$ & 2 & $\mathrm{Y}$ & 1 \\
8 & $\mathrm{Y}$ & 2 & $\mathrm{Y}$ & 3 & $\mathrm{Y}$ & 1 & $\mathrm{Y}$ & 2 & $\mathrm{~N}$ & 0 & $\mathrm{Y}$ & 2 & $\mathrm{Y}$ & 2 & $\mathrm{Y}$ & 1 & $\mathrm{Y}$ & 1 \\
9 & $\mathrm{Y}$ & 4 & $\mathrm{~N}$ & 2 & $\mathrm{Y}$ & 2 & $\mathrm{Y}$ & 1 & $\mathrm{Y}$ & 1 & $\mathrm{~N}$ & 0 & $\mathrm{Y}$ & 2 & $\mathrm{Y}$ & 1 & $\mathrm{Y}$ & 1 \\
10 & $\mathrm{Y}$ & 1 & $\mathrm{Y}$ & 2 & $\mathrm{Y}$ & 2 & $\mathrm{~N}$ & 1 & $\mathrm{Y}$ & 1 & $\mathrm{Y}$ & 1 & $\mathrm{Y}$ & 2 & $\mathrm{Y}$ & 2 & $\mathrm{~N}$ & 0 \\
11 & $\mathrm{Y}$ & 2 & $\mathrm{Y}$ & 1 & $\mathrm{Y}$ & 3 & $\mathrm{Y}$ & 3 & $\mathrm{Y}$ & 1 & $\mathrm{Y}$ & 2 & $\mathrm{Y}$ & 3 & $\mathrm{Y}$ & 1 & $\mathrm{Y}$ & 4 \\
12 & $\mathrm{Y}$ & 1 & $\mathrm{Y}$ & 2 & $\mathrm{~N}$ & 1 & $\mathrm{~N}$ & 0 & $\mathrm{Y}$ & 1 & $\mathrm{~N}$ & 1 & $\mathrm{Y}$ & 1 & $\mathrm{Y}$ & 1 & $\mathrm{~N}$ & 1 \\
13 & $\mathrm{~N}$ & 0 & $\mathrm{~N}$ & 1 & $\mathrm{~N}$ & 1 & $\mathrm{~N}$ & 0 & $\mathrm{~N}$ & 0 & $\mathrm{~N}$ & 0 & $\mathrm{Y}$ & 1 & $\mathrm{~N}$ & 0 & $\mathrm{Y}$ & 1 \\
14 & $\mathrm{~N}$ & 1 & $\mathrm{Y}$ & 1 & $\mathrm{~N}$ & 0 & $\mathrm{Y}$ & 1 & $\mathrm{~N}$ & 0 & $\mathrm{Y}$ & 2 & $\mathrm{Y}$ & 1 & $\mathrm{Y}$ & 1 & $\mathrm{Y}$ & 1 \\
15 & $\mathrm{Y}$ & 1 & $\mathrm{Y}$ & 1 & $\mathrm{Y}$ & 1 & $\mathrm{Y}$ & 2 & $\mathrm{Y}$ & 2 & $\mathrm{Y}$ & 1 & $\mathrm{Y}$ & 1 & $\mathrm{Y}$ & 2 & $\mathrm{Y}$ & 2 \\
\hline
\end{tabular}

All prints that obtained a score of 3 or 4 , deemed as identifiable, have been highlighted in light grey (14). Prints that obtained a 0 , where no development of the print is present, are shown in darker grey. An example of an excellent print is shown in Figure 7 and an example of an 'empty' print, one that shows no ridge detail but indication of being grabbed is shown in Figure 8.
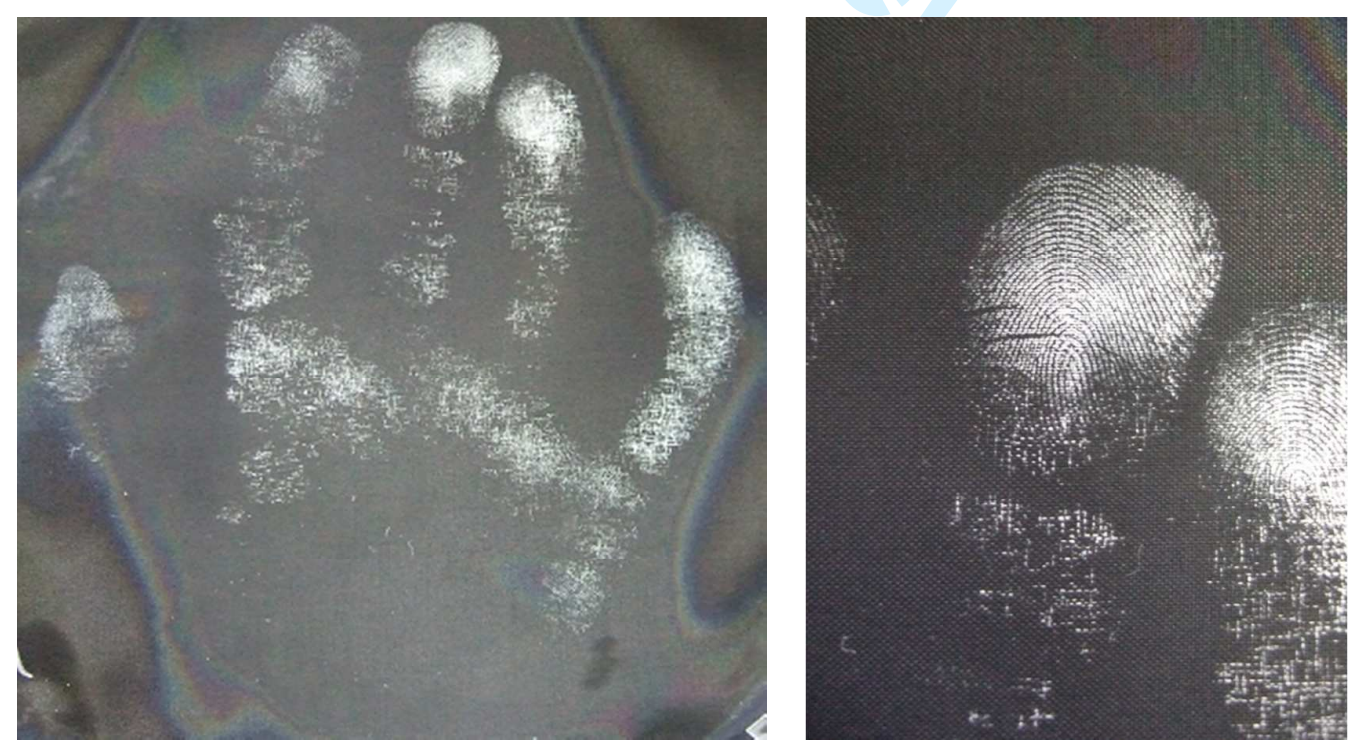
1

2

3

4

5

6

7

8

9

10

11

12

Figure 7 Example of an identifiable print and an enlargement of one of the fingerprints

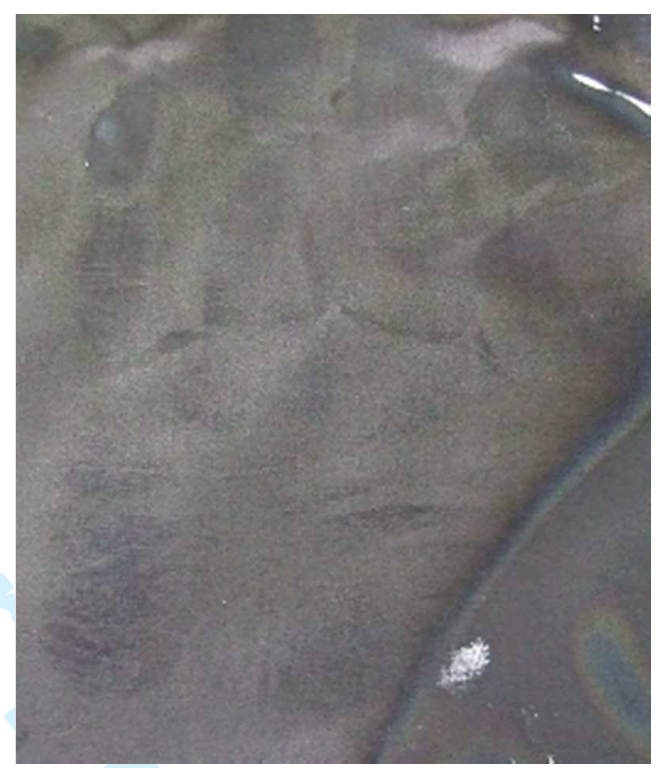

Figure 8 Example of an empty print - one that shows no ridge detail but evidence of being grabbed

\section{Discussion}

The work described in this manuscript has been shown that a method for the enhancement of fingerprints on fabric has been successfully developed by use of FT-IR mapping after cyanoacrylate fuming and can be compared to the method proposed by Fraser et al. (4) using vacuum metal deposition.

When looking at Table 3, it can be seen that while most of the good scores (those graded with a 3 or a 4 and deemed as identifiable, shaded in light grey) occur towards the beginning of the experiment, good scores are still obtained at 28 days showing that on this 
time scale, prints do not significantly age and can still be enhanced up to 28 days after application. It can be assumed that, although the experiment did not cover any further time points, some prints would be successfully enhanced at times beyond 28 days. It is possible that the method of storing the prints in plastic wallets in the dark may reduce the natural ageing of the prints, and so a further study could be carried out to determine if different methods of storing the prints might affect the rate at which the prints degrade.

Prints that were graded a 0 , where no print is present, are shown in darker grey. These scores are quite evenly spread and do not seem to become more frequent as the prints get older. Some donors are more likely to have mostly scores of 0 or to obtain mostly good scores, but there are still cases such as donors 5 and 6 who have obtained both good scores and scores of 0 , giving very mixed results. This indicates that ageing is not a large factor in this experiment, but instead individual variation in fingerprint composition is a much greater factor. The results also show that fingerprint composition from a single donor can vary greatly between each print, and so someone classed as a good donor, may still give bad prints. However, there are a great deal of good quality prints showing that this method works well and is quite repeatable.

Figure 9 shows the distribution of scores obtained from the prints on polyester graphically to clearly show the range of scores achieved. The majority of prints were graded with a score of 1 , with a score of 2 having the next largest number of prints. Scores 3 and 4 show fewer prints; this is as expected. 


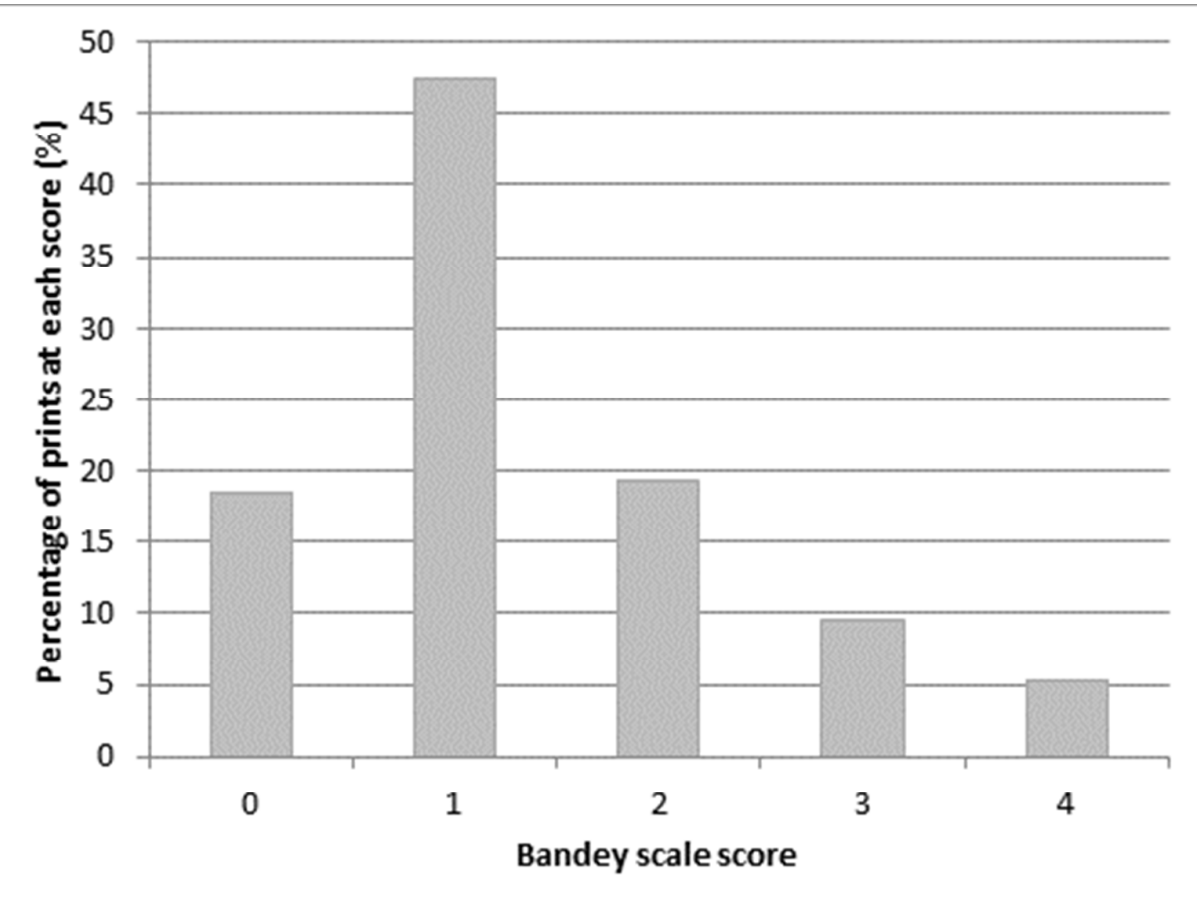

Figure 9 Distribution of Bandey scale scores of prints developed on polyester at all time points

When these results are compared to those obtained by Fraser et al. (4) (shown in Figure 10) it can be seen that the method proposed in this work provides better results than the vacuum metal deposition method proposed by Fraser. The table shows the percentage of prints that were graded at each score for all time points for each of the two methods. It can be seen that the percentages of prints graded with a score of 0,1 or 2 are lower for this method, while the percentages of prints with a score of 3 or 4 , those that are identifiable, are significantly higher in this study than in the previous study by Fraser et al. As different donors were used in the two studies, and relatively small sample sizes were used, the comparison of results should be taken with caution as they cannot be truly compared without using the same donors; however the results show that this method can give improved results for the enhancement of fingerprints on polyester fabric. 


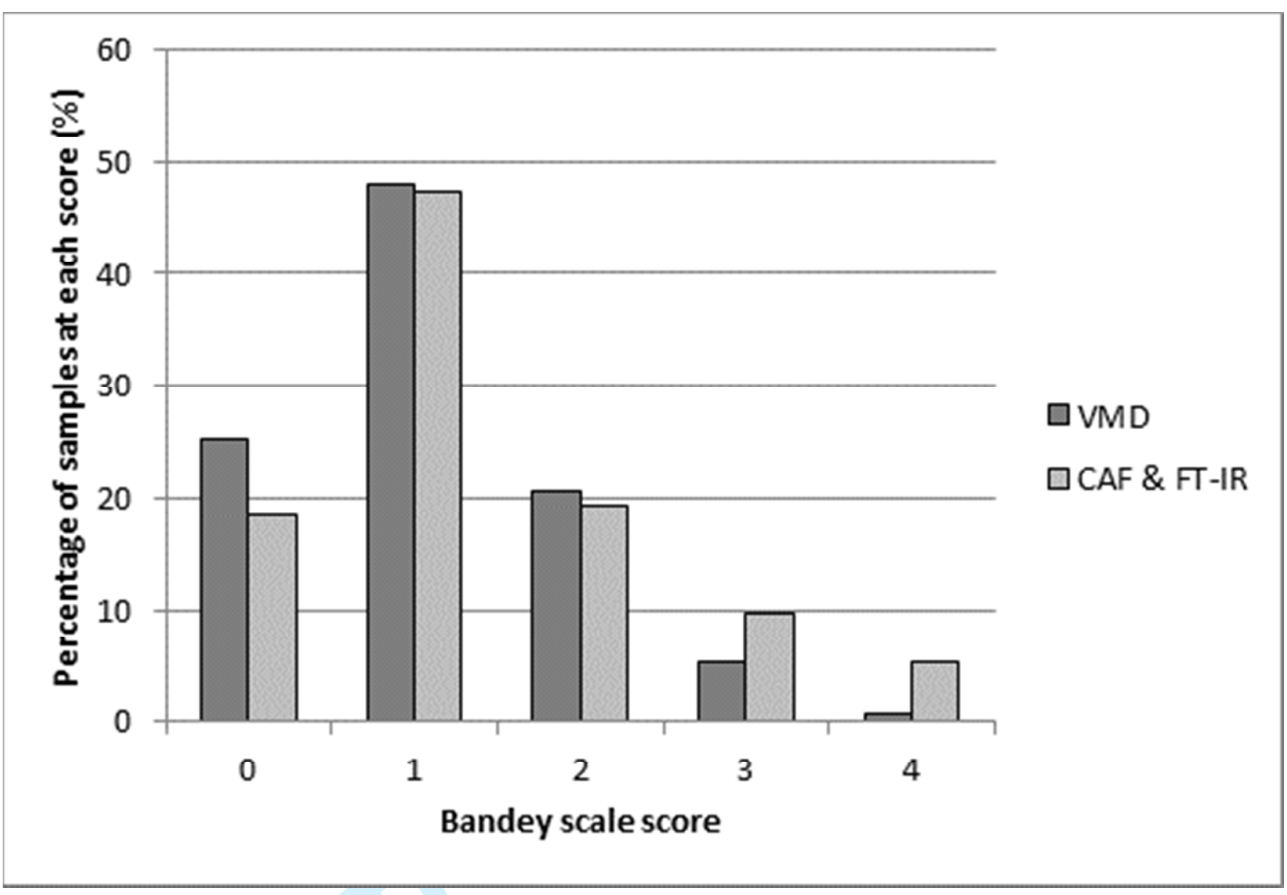

Figure 10 Comparison of the percentages of each score for the two studies; VMD and CAF \& FT-IR on polyester fabric

Figure 11 shows the numbers of prints with either ridge detail or palmar flexion creases (indication of a grab mark) for each day, with large numbers of prints achieving these criteria. It can be seen that there is very little decrease in the numbers of prints achieving these two criteria with time, with no real downward trend observed. This again shows that ageing is not a significant factor in this experiment. While this graph does not indicate whether a print can be identified or not, it has been produced as a way of comparing results with other researchers' work. When these results are compared to those achieved by Fraser et al. (4) it can be seen that these results give a greater number of prints with ridge detail and palmar flexion creases. In the research described in this paper, not less than $60 \%$ of prints showed ridge detail on any one day, and not less than $73 \%$ of prints showed palmar flexion creases on any one day. When compared to previous work by Fraser et al., there was one day where no prints showed any ridge detail, while a maximum of $30 \%$ of prints showed ridge detail on any one day. A minimum of $7 \%$ of prints showed palmar flexion creases while the maximum 


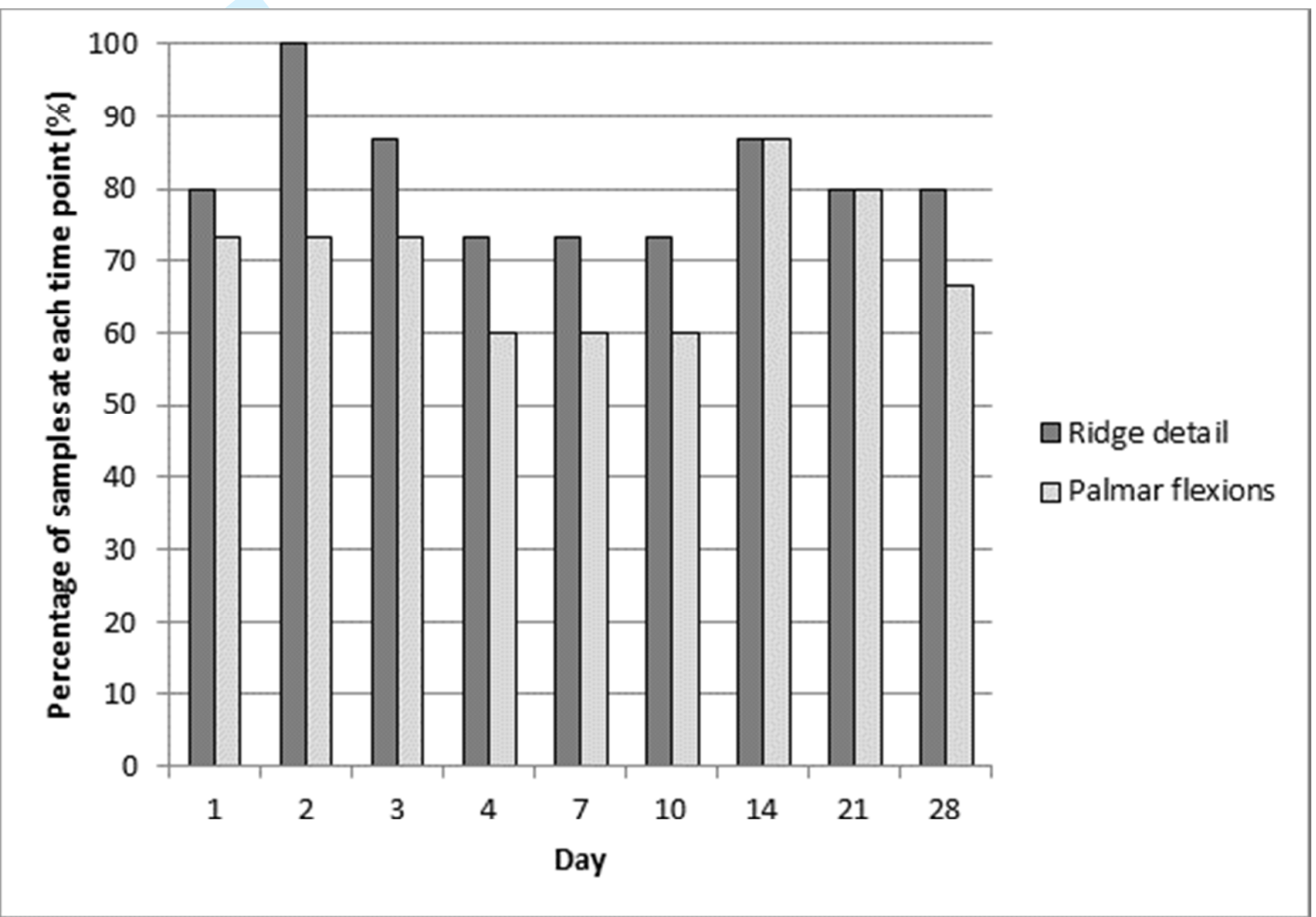

Figure 11 Graph to show the percentage of samples containing ridge detail and palmar flexion creases of the prints developed on polyester on each day

This research described here used only polyester fabric to test the method, while other researchers have used multiple fabrics to see which gives the best results. The work by Fraser et al. (4) showed that nylon, followed by polycotton were the best fabrics for the vacuum metal deposition method, and that polyester and cotton were not as successful. This study could be further developed to test other fabrics to see if it is as successful. It has already been 
determined that nylon is a suitable fabric for the CAF \& FT-IR method, along with acetate and silk, but cotton and polycotton have not been successful. It would therefore be appropriate for this study to be expanded to include a wider range of fabrics, as well as a greater number of donors to fully assess the reliability of the method.

It has not been possible to enhance fingerprints on any cotton or polycotton fabrics in this research. The work discussed previously by Fraser (4) was quite successful on polycotton fabric, but had little success on cotton fabric. It would therefore be reasonable to suggest that the method of vacuum metal deposition would be an appropriate method for the enhancement of prints on polycotton fabric. There is however, no technique that has shown to enhance prints on cotton fabric to date. This is clearly an area that requires further work.

While not all prints in this chapter were enhanced to a standard required for identifying an individual, all prints that show some enhancement may be of use in a forensic environment. Prints on fabric for example, maybe from a rape or assault case, may help to confirm or disprove the victim's account of events. For example, if the victim states that they were grabbed from behind or pushed, it would be expected that the shape and location of any print or grab mark would confirm this.

\section{Conclusion}

A method has successfully been developed for the enhancement of fingerprints on fabric by infrared microscopy. The method has been shown to work on polyester, silk, nylon 
and acetate fabrics of different colours and patterns and has shown an improvement over existing proposed methods. It would be quite possible for this method to be adopted by forensic practitioners. It has been shown that ageing has little effect on the results of the method for the time scale that has been studied here. However, the donor themselves has the greatest impact on how successful the method is. This has been demonstrated in this research where the success of enhancement of different donors' fingerprints has shown to vary greatly. Differences were also found in the success of prints given by the same donor at different times. This reinforces the idea that fingerprint residue composition varies greatly and can have an effect on the results of enhancement experiments.

Prints on smooth, shiny fabrics can now be enhanced with cyanoacrylate fuming followed by infrared mapping, giving ridge detail and producing prints that are of a quality good enough to be identified by a fingerprint expert. This is something that previously there was no accepted method for and could not be done. A significant improvement to the enhancement of prints on difficult surfaces has been made in this research. 
${ }^{1}$ Bowman V. Manual of fingerprint development techniques. $2^{\text {nd }}$ ed, $3^{\text {rd }}$ rev. Luton: White Crescent Press Ltd. 1998

${ }^{2}$ Beresford AL, Hillman AR. Electrochromic enhancement of latent fingerprints on stainless steel surfaces. Analytical Chemistry 2010;82:483-6

${ }^{3}$ Beresford AL, Brown RM, Hillman AR, Bond JW. Comparative study of electrochromic enhancement of latent fingerprints with existing development techniques. Journal of Forensic Sciences 2012;57:93-102

${ }^{4}$ Fraser J, Sturrock K, Deacon P, Bleay S, Bremner DH. Visualisation of fingermarks and grab impressions on fabrics. Part 1: Gold/zinc vacuum metal deposition. Forensic Science International 2010;208:74-8

${ }^{5}$ Knighting S, Fraser J, Sturrock K, Deacon P, Bleay S, Bremner DH. Visualisation of fingermarks and grab impressions on dark fabrics using silver vacuum metal deposition. Science and Justice 2013;53:309-14

${ }^{6}$ Fraser J, Deacon P, Bleay S, Bremner DH. A comparison of the use of vacuum metal deposition versus cyanoacrylate fuming for visualisation of fingermarks and grab impressions on fabric. Science and Justice 2014;54:133-40

${ }^{7}$ Jones N, Stoilovic C, Lennard C, Roux C. Vacuum metal deposition: developing latent fingerprints on polyethylene substrates after deposition of excess gold. Forensic Science International 2001;123:5-12

${ }^{8}$ Crane NJ, Bartick EG, Schwartz Perlman R, Huffman S. Infrared spectroscopic imaging for noninvasive detection of latent fingerprints. Journal of Forensic Sciences 2007;52:48-53 
${ }^{9}$ De Sousa J, Cheatham C, Wittbrodt M. The effect of a moisture-wicking fabric shirt on the physiological and perceptual responses during acute exercise in the heat Applied Ergonomics 2014;45:1447-53

${ }^{10}$ Nixon C. Regeneration of aged fingerprints using the "superglue" technique.[Dissertation] Reading (UK): Univ. of Reading, 2009

${ }^{11} \mathrm{http}: / /$ www.omega.com/temperature/Z/pdf/z103.pdf

${ }^{12} \mathrm{http}$ //www.fosterfreeman.com/fingerprint-evidence/295-mvc-fuming-cabinet-3.html

${ }^{13}$ Bandey HL. Fingerprint Development and Imaging Newsletter: The Powders Process, Study 1, Sandridge: Police Scientific Development Branch, Home Office; 2004. Report No. $54 / 04$

${ }^{14}$ Beresford AL, Brown RM, Hillman AR, Bond JW. Comparative study of electrochromic enhancement of latent fingerprints with existing development techniques. Journal of Forensic Sciences 2012;57:93-102 